For reprint orders, please contact: reprints@futuremedicine.com

\title{
Vaccine-based immunotherapy for glioblastoma
}

\author{
Alissa A Thomas' , Jan L Fisher', Marc S Ernstoff' \& Camilo E Fadul*1
}
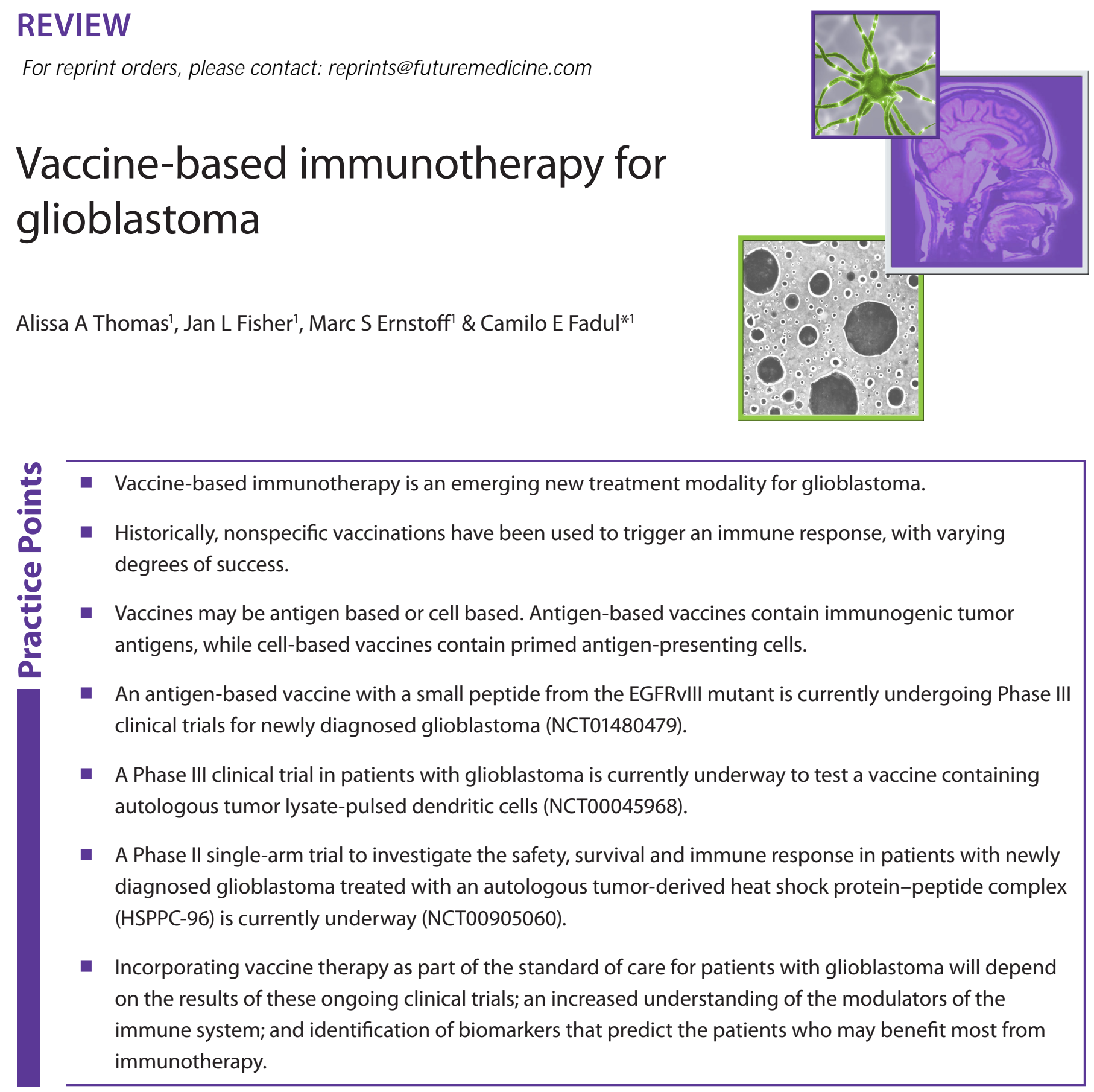

SUMMARY Glioblastoma remains the most lethal human brain tumor, despite the advent of multimodal treatment approaches. Because immune tolerance plays an important role in tumor progression, adding immunotherapy has become an attractive and innovative treatment approach for these aggressive tumors. Several early-phase clinical trials have demonstrated that vaccine-based immunotherapies, including dendritic cell therapy, peptide-based vaccines and vaccines containing autologous tumor lysates, are feasible and well tolerated. These trials have revealed promising trends in overall survival and progression-free survival for patients with glioblastoma, and have paved the way for ongoing randomized controlled trials.

'Dartmouth Hitchcock Medical Center, Geisel School of Medicine at Dartmouth, Norris Cotton Cancer Center, 1 Medical Center Drive, 
Glioblastoma, the most frequent and aggressive brain tumor, remains a deadly disease [1]. Despite improved outcomes following surgery, radiation therapy and chemotherapy, the median survival for patients is just over 1 year [2]. The antiangiogenesis drug bevacizumab appears to increase progression-free survival in many patients during disease progression [3,4]; however, even after an initial response, all patients eventually succumb to progressive disease. Individual patient characteristics and tumor genetics may predict longer survival. One of the most important prognostic factors for overall survival is the epigenetic silencing of the MGMTDNA repair gene $[2,5,6]$. Immune response also correlates with survival [7]. Based on microarray studies with high-grade gliomas, increased expression of immune-related genes correlates positively with increased survival. Infiltration of T cells, microglia and macrophages into the tumor correlates positively with survival.

New therapeutic modalities are needed to improve the poor outcomes in patients with glioblastoma given conventional treatments. Glioblastoma is a heterogeneous tumor with multiple cell types, some of which have stem cell-like properties and others that are tumorigenic. Additionally, the interaction between the tumor cells and the surrounding parenchymal cells, including peripheral immune cells, vascular cells, microglia and neuronal precursors, may contribute to tumor pathology [8]. This so-called tumor microenvironment has gained considerable interest as a therapeutic target for immunotherapy. The rationale for immunotherapy in glioblastoma is derived from the observation that tumor-specific immune tolerance may play a role in tumor progression $[9,10]$. We know that antiglioma immune responses that occur in patients correlate with survival. Nevertheless, early trials to treat glioblastoma with a variety of immune therapeutic approaches, including cytokines, monoclonal antibodies, cytotoxic lymphocytes and vaccines, reported discouraging results [11-13]. Limitations of immunotherapy for glioblastoma are imposed by the production of immunosuppressive cytokines by glioma cells, the blood-brain barrier that restricts access of effector immune cells to the nervous system and the use of steroids to control brain edema. Such considerations should be taken into account when designing a clinical trial using immunotherapy for brain tumors.

A more complete understanding of the interaction between the nervous and immune systems in healthy and pathologic states has allowed for a more rational approach to developing immunotherapies for brain tumors. While the normal brain has few circulating $T$ cells and an absence of naive T cells [14], T cells activated in cervical lymph nodes are able to move into the CNS [14]. Under physiologic conditions, microglial cells are among the first lines of immune defense for the brain [15]. Perivascular cells, such as microglia, can function as antigen-presenting cells (APCs).

An emerging concept is that glioblastoma not only induces a local and systemic immunesuppressive environment, but that the tumor thrives by evading the immune system. Populations of activating/effector immune cells and suppressive/regulatory cells intrinsic to the healthy immune system detect foreign invaders while preventing autoimmunity. However, in patients with glioblastoma, the balance of immune cells may shift, and cells that dampen the immune response, such as regulatory $\mathrm{T}$ cells (Tregs), may prevail. Patients with gliomas have relatively ineffective peripheral blood $\mathrm{T}$ cells, that are deficient in IL-2 secretion and have decreased expression of high-affinity IL-2 receptors $[16,17]$. In patients with glioblastoma, frequency of peripheral $\mathrm{CD}^{+} \mathrm{T}$ cells are decreased, but within that population, the proportion of Tregs is increased. This has been reported both before treatment in one study [18], and after radiation and chemotherapy in another study [19] and appears to increase overall survival. In patients with newly diagnosed, high-grade gliomas treated with surgery, radiation therapy and chemotherapy, the $\mathrm{CD} 4^{+} \mathrm{T}$-cell count 2 months post-treatment correlated with survival [20]. In this study, $40 \%$ of the patients with $\mathrm{CD} 4^{+}$ counts $<200$ cells $/ \mathrm{mm}^{2}$ had a significantly shorter median survival of 13.1 months compared with 19.7 months in patients with higher $\mathrm{CD} 4^{+}$counts. There also appears to be a direct correlation between survival and glioblastoma tumor infiltration by effector $\mathrm{T}$ cells, including cytotoxic and helper $\mathrm{T}$ cells [21]. On the other hand, tumor infiltration by immunosuppressive $\mathrm{T}$ cells, or Tregs, has been reported to negatively correlate with survival across various grades of glial neoplasms [22]. Taken together, these data suggest that the balance of effector $T$ cells and Tregs in the tumor microenvironment influence survival in patients with glioblastoma. Nevertheless, methodological approaches may affect the interpretation, and there are two key differences between these studies [21,22]. In the 
first study, all patients had glioblastoma [21]. The survival advantage correlated with increased effector $T$ cells. In the second study, patients with glial tumors of all grades were included [22]. The survival disadvantage was for patients with increased suppressive Tregs, but these patients also had higher-grade tumors. More studies are needed to understand the immune profile in the glioblastoma microenvironment and how it relates to outcome.

The term immunotherapy encompasses a spectrum of strategies that have been categorized as active or passive, according to the role of the individual's immune system in the antineoplastic effect. Active immunotherapy boosts the patient's immune system by priming it with antigen exposure. This is in contrast to passive immunotherapy, in which patients are given effector cells, monoclonal antibodies or cytokines. In patients with gliomas, immune responses to passive immunotherapy have been mediocre at best, but active immunization strategies using vaccines have shown encouraging results in Phase I and II trials, which will be discussed in this article. With active immunization, patients are vaccinated with a tumor antigen, which is recognized by the adaptive immune system as foreign, in turn triggering an immune response targeted to the tumor. Some of the vaccine strategies are antigen based and depend on APCs to activate the immune system, while other strategies use professional APCs, the dendritic cells (DCs), which are activated ex vivo and then given to the patient to stimulate effector immune cells. These different vaccine strategies are categorized in Figure 1.

One challenge in designing clinical trials for immunotherapy is determining the trial end point. Vaccine trials are labor intensive and expensive with some trials requiring personalized vaccines to be made for each enrolled patient. Therefore, vaccine trials are often small and the traditional end points, such as overall survival and progression-free survival, are unreliable and may not capture vaccine response. Thus, surrogate end points of immune response are reported. When the antigen is known, antigenspecific immune responses may be reported in the trial. In other trials, general measures of immune activation may be reported, such as T-cell profiles or cytokine concentrations.

This article focuses on the vaccine approaches for treating glioblastoma, emphasizes the outcomes and lessons learned from published clinical trials, and presents strategies that are being studied to optimize their efficacy. Although the role of vaccines in the standard management of glioblastoma is yet to be determined, the results of ongoing Phase III trials will probably determine the fate of vaccines as a viable addition to the multimodal treatment of high-grade gliomas.

\section{Vaccine strategies}

Antigen- and cell-based vaccines differ in the way tumor antigens are presented to the immune

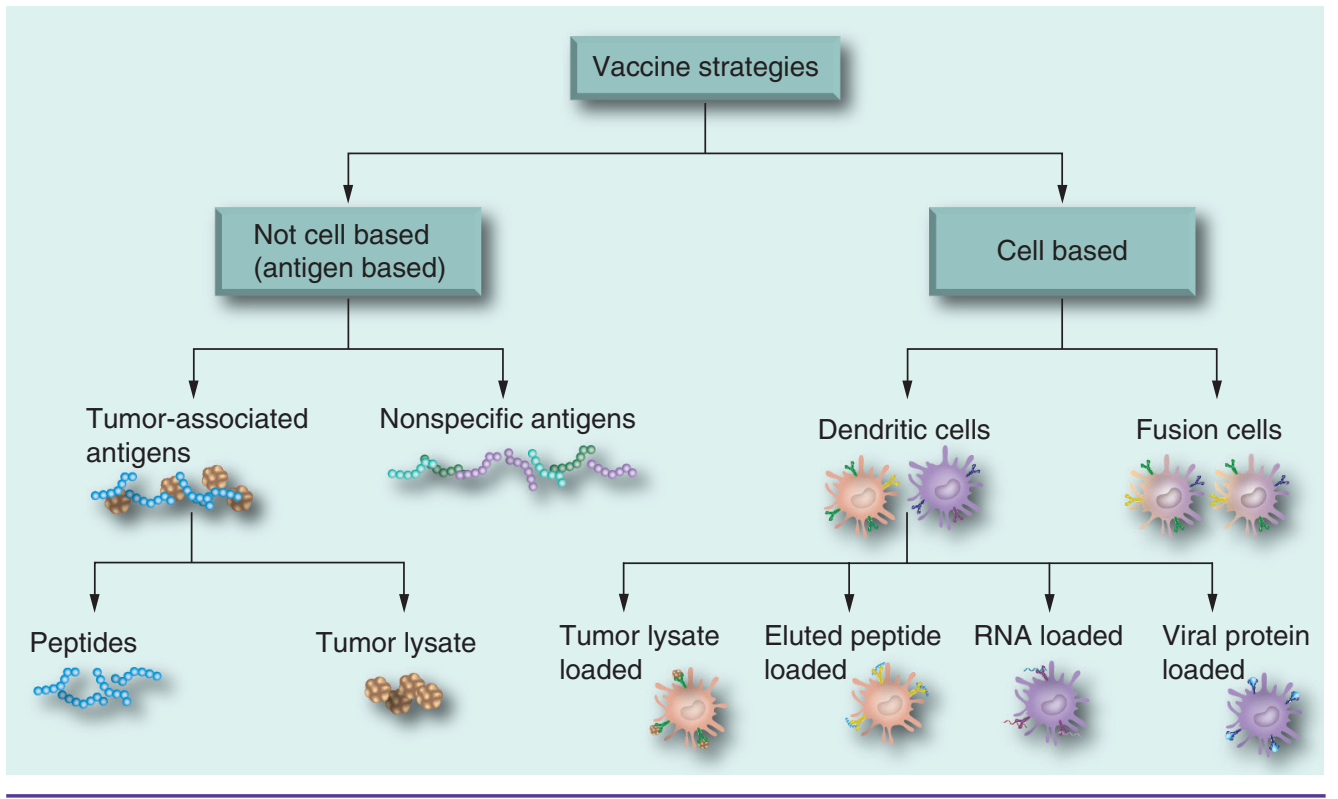

Figure 1. Vaccine strategies. 
system. Figure 2 broadly illustrates how vaccines can stimulate an immune response to a tumor. With antigen-based vaccines, patients are directly vaccinated with the antigen, which is then detected, processed and presented by APCs in vivo. The earliest studies used nonspecific antigens, those unrelated to the tumor but capable of inducing an immune response. We now know that tumors express a variety of antigens, described as either tumor-specific antigens, when they are expressed only by the tumor, or tumor-associated antigens, when they are expressed by the tumor as well as by other cells. When vaccinated, patients may be given peptides in the form of 'peptide-based vaccines' [23-26]. Many peptide vaccines use nine amino acids, as this is the length of peptide that binds to the HLA class I pocket; these are necessary for antigen recognition. Peptide vaccines may also be administered as a cocktail of multiple immune-dominant nine amino acid strings, or as an array of antigens in the form of a wholetumor lysate [27-29]. Peptide vaccines may be coadministered with viruses or viral vectors [30], with cytokines [31] or as fusions to other proteins [25] to further stimulate the immune response to the vaccine.

By contrast, cell-based vaccines are composed of APCs that have already been primed with tumor antigens ex vivo. In clinical trials, peripheral blood monocyte-derived DCs are the APCs most frequently used for cell-based vaccines [32]. The monocytes are cultured ex vivo with growth factors and tumor antigens to produce mature activated DCs, which are then administered to the patient. Figure 3 illustrates how DC vaccines are prepared, administered and monitored by different methods. Similar to peptide vaccines, the autologous tumor antigens can be derived from various sources, including whole-tumor lysates [33-46], eluted peptides [47,48], RNA [49] or fusions of dendritic and glioma cells [50,51].

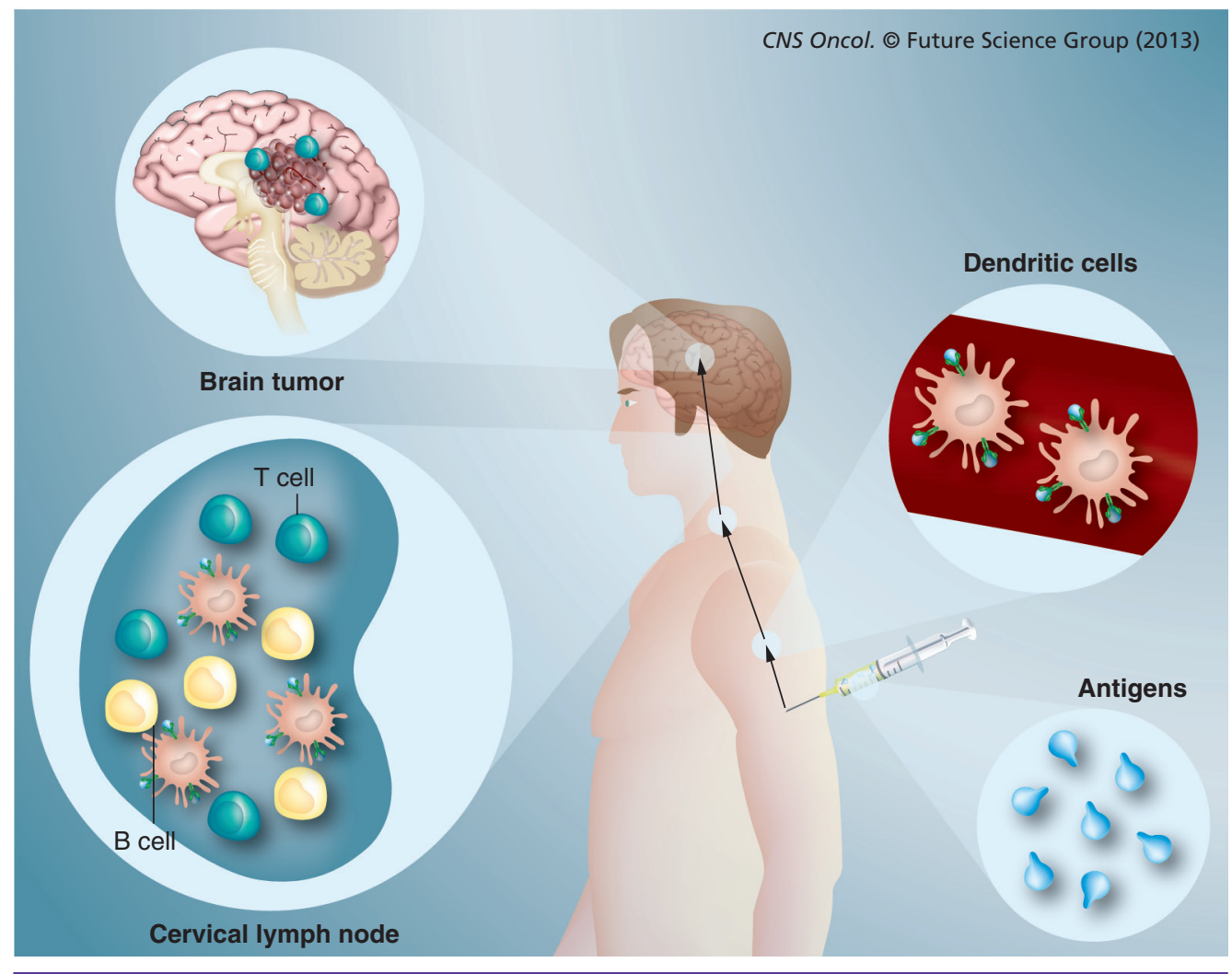

Figure 2. Antigen presentation in the CNS from a vaccine. Antigen-based vaccines can be administered subdurally, intradurally, intramuscularly, intranodally or intravenously. The antigens are taken up by antigen-presenting cells, typically dendritic cells, and then migrate to the cervical lymph node. In the cervical lymph node, activated antigen-presenting cells stimulate $T$ cells. The activated T cells migrate out of the node and into the CNS to mount a cell-based immune response against the tumor. 


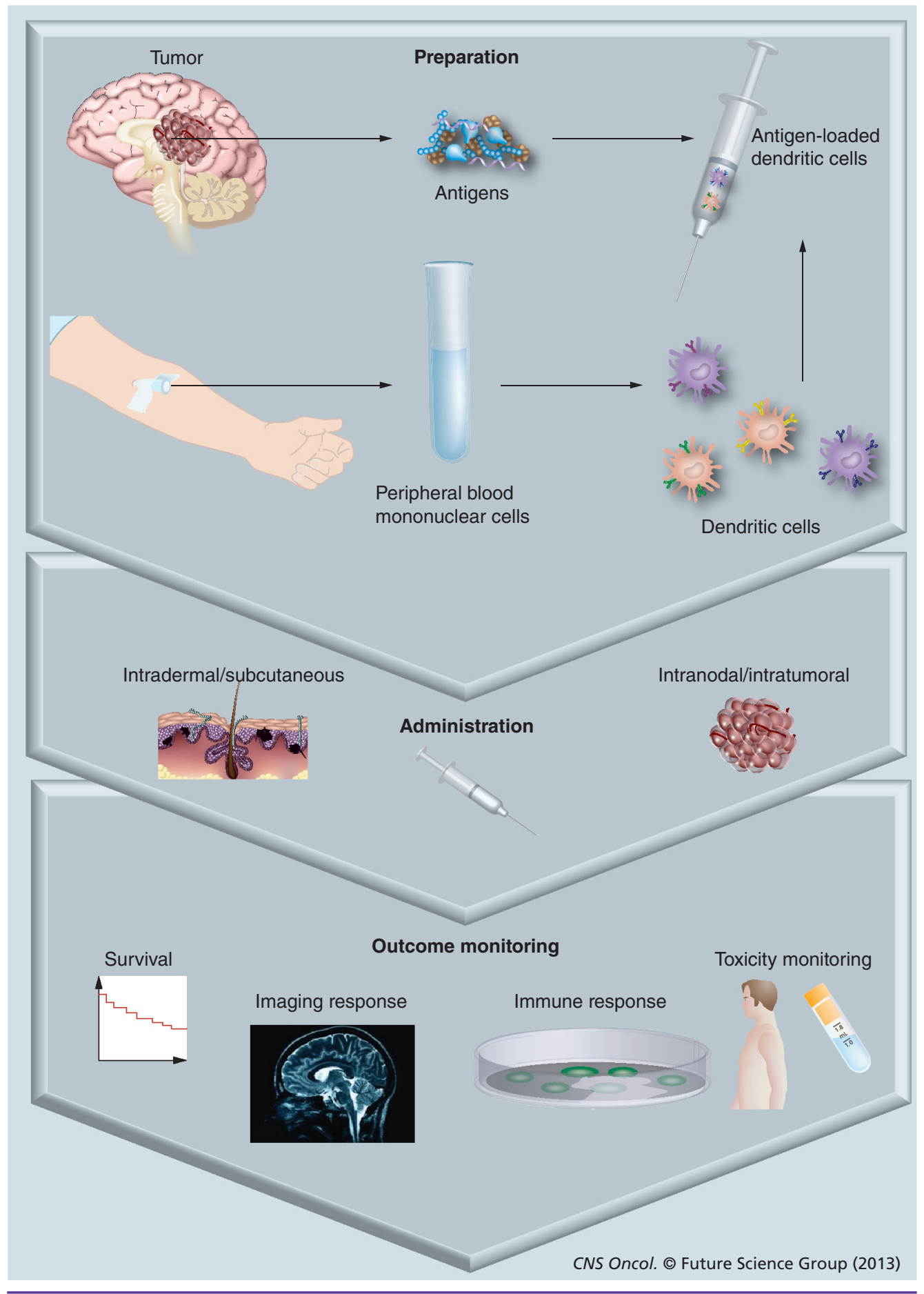

Figure 3. Vaccination strategy. There are three steps to vaccination for gliomas: preparation; administration; and outcomes monitoring. In the preparatory step, the tumor is harvested and the antigen is prepared from the tumor lysate or tumor peptide. With dendritic cell vaccines, the tumor antigens are then exposed to dendritic cells derived from peripheral blood mononuclear cells ex vivo. The activated dendritic cells are then administered to the patient by various routes. The patient is observed for immune response, radiographic response, clinical response to the vaccine and toxicity. 
Clinical experience with vaccines for treatment of glioblastoma

- Nonspecific vaccination

Over a century ago, William Coley reported that patients with cancer who experienced surgical infections may have an improved survival [52]. He put the theory into practice by injecting strains of bacteria, called 'Coley's toxins', directly into inoperable tumors, which showed some success [52]. We now understand that it is not the infection itself that prolongs survival from malignancy, but the immune activation triggered by the infection. Infection can activate immune pathways via pathogen-associated molecular patterns and activation of Toll-like receptors (TLRs), which subsequently initiate anti-tumor immunity.

Anecdotal evidence suggests that patients with glioblastoma who have perioperative surgical cavity infections tend to survive longer. A recent retrospective study reported that, among 197 patients with malignant glioma, a small subset of ten patients with perioperative infections had a significant advantage in median survival: 30 months compared with 15 months in those patients without infection [53].

Based on these observations, various bacterial lipopolysaccharides have been investigated for treating cancer [54]. A published report of a vaccine for glioblastoma first appeared in 1980 [55], which described treating a brain tumor with a Bacillus Calmette-Guerin (BCG) cell wall preparation, developed from an attenuated strain of Mycobacterium bovis. The first application of BCG was used to prevent tuberculosis, but the nonspecific immune activation caused by this bacteria generated interest for cancer applications. In a subsequent clinical trial of 20 patients with malignant gliomas, patients were actively immunized subcutaneously with glioma tissue culture cell lines (D-54MG or U-251MG) with the addition of BCG for the first inoculation together with radiation therapy and chemotherapy with bis-chloroethylnitrosourea, an alkylating agent [56]. The patients who received U-251MG had a longer survival compared with patients treated with D-54MG or historic controls.

In the late 1980s and early 1990s, there was a series of experiments with a vaccine derived from Serratia marcescens, called ImuVert [57-59], a biologic response modifier composed of natural membrane vesicles associated with ribosomes derived from Serratia marcescens. The first clinical study of ImuVert included 39 patients with various tumor types, including one patient with glioblastoma [57]. The patients were given a series of subcutaneous vaccinations once a week for a minimum of 3 weeks. The vaccinations were well tolerated, and the one patient with glioblastoma had a minor response to the treatment, defined by a $25-50 \%$ decrease in tumor diameter. From this somewhat encouraging response, a Phase II trial of ImuVert for recurrent malignant glioma was undertaken, in which 19 patients with recurrent glioblastoma or anaplastic astrocytoma were vaccinated once a week for 5-week cycles followed by a 2 -week rest period [58]. Two patients had a complete response to treatment, which lasted 63 and $\geq 77$ weeks ( 16 and 19 months, respectively). One patient had a transient minor response that lasted for 6 weeks. ImuVert was also used in 15 patients with newly diagnosed glioblastoma or anaplastic astrocytoma [59]. Again, the vaccines were generally well tolerated with the exception of local injection-site reactions, and some of the patients experienced hypotension requiring fluid resuscitation and pressors. Two of the four patients with anaplastic astrocytoma were followed in the study for 131 and 139 weeks ( 32 and 34 months, respectively) without evidence of disease progression. All patients with glioblastoma progressed, with a median time to progression of 11 weeks.

Nearly 20 years later, new studies began appearing using Newcastle disease virus (NDV) [60]. The first promising study in 1999 from Hungary used a strain of NDV dubbed 'More Than Hope 1968' in one patient [60]. In 2001, Schneider and colleagues treated 11 newly diagnosed glioma patients who had undergone surgery and radiation therapy with inactivated autologous tumor cells infected with NDV [27]. They reported a median survival of 46 weeks ( 11 months). The advantage of NDV is that, as a ssRNA virus, it poses little health hazard to humans. It can selectively infect tumor cells triggering immune responses that promote antitumor immunity. A summary of nonspecific vaccines is presented in Table 1.

\section{- Antigen-based vaccines}

Current experience with antigen-based vaccines includes Phase I and II trials with several different kinds of antigens, including a small peptide from the mutated EGFR, 'cocktails' of multiple small peptides, autologous tumor lysates and heat shock proteins (Table 2). 
Table 1. Clinical trials of vaccines with nonspecific antigens.

\begin{tabular}{|c|c|c|c|c|c|}
\hline Study (year) & Patients (n) & Vaccine substrate & $\begin{array}{l}\text { Median overall } \\
\text { survival (weeks) }\end{array}$ & Toxicity & Ref. \\
\hline $\begin{array}{l}\text { Bergquist et al. } \\
\text { (1980) }\end{array}$ & 1 & BCG & - & - & [55] \\
\hline $\begin{array}{l}\text { Mahaley et al. } \\
\text { (1983) }\end{array}$ & $20 \mathrm{HGG}$ & BCG & - & - & [56] \\
\hline $\begin{array}{l}\text { Mittelman et al. } \\
\text { (1992) }\end{array}$ & 39,1 with GBM & ImuVert & - & - & [57] \\
\hline $\begin{array}{l}\text { Jaeckle et al. } \\
\text { (1990) }\end{array}$ & 19 GBM & ImuVert & 19 & Transient, low grade & [58] \\
\hline Black et al. (1993) & 15 HGG & ImuVert & 78 & Hypotension & [59] \\
\hline $\begin{array}{l}\text { Csatary and } \\
\text { Bakacs (1999) }\end{array}$ & - & NDV & - & - & [60] \\
\hline $\begin{array}{l}\text { Schneider et al. } \\
\text { (2001) }\end{array}$ & $11 \mathrm{GBM}$ & NDV & 46 & None & [27] \\
\hline
\end{tabular}

\section{EGFR-targeted vaccines}

EGFR has received significant attention as a vaccine target, because in approximately $20-30 \%$ of glioblastoma cases, it is mutated from its wild-type form to EGFRvIII [26]. This tumorspecific antigen is expressed on other tumors, including breast, ovarian, head and neck, and non-small-cell lung cancers, but not on normal tissue. A 14-amino acid peptide unique to EGFRvIII called PEP-3 or PEPvIII, coupled to a helper molecule, keyhole limpet hemocyanin (KLH), has been used as a vaccine to generate EGFRvIII-specific antibodies [23-26]. This compound, called PEPvIII-KLH, CDX-110 or rindopepimut, is currently being studied in clinical trials.

In the first clinical trial using this vaccine, 15 patients with newly diagnosed glioblastoma were enrolled, but three were later excluded due to disease progression during radiation therapy [25]. The eligible patients were vaccinated with DCs pulsed with PEPvIII-KLH and given three intradermal vaccines every 2 weeks. The vaccination was well tolerated with no grade 3 toxicities. Immunization induced antigen-specific cellular and humoral immune responses, with patients having a longer survival compared with historical controls.

These encouraging results paved the way for two Phase II clinical trials, called ACTIVATE [24] and ACT III [23]. In ACTIVATE, 18 patients with newly diagnosed EGFRvIII-expressing glioblastoma were treated with intradermal vaccines containing PEPvIII-KLH. Patients experienced injection-site reactions, but no more than grade 2 toxicities from the vaccine. The median time to progression was 14.2 months, and overall survival was 26 months, significantly longer than matched controls treated with the standard of care. At the time of tumor recurrence, some patients underwent re-resection or biopsy and $82 \%$ of the recurrent tumors had lost EGFRvIII expression. Six patients with a humoral immune response to the vaccine, detected in their serum, reported a median survival of 47.7 months compared with 22.8 months in the other 12 patients. The next study compared PEPvIII-KLH vaccination combined with either standard dosing of temozolomide $\left(200 \mathrm{mg} / \mathrm{m}^{2}\right.$ dose on days 1-5 of every 28 days) or with dose-intense temozolomide $\left(100 \mathrm{mg} / \mathrm{m}^{2}\right.$ dose on days $1-21$ of every 28 days) [23]. Twenty two patients were enrolled in the study. Although all patients developed EGFRvIII-specific humoral responses, patients treated with dose-intense temozolomide showed enhanced humoral and cellular immune responses despite more severe lymphopenia compared with patients receiving the standard temozolomide dose. In this trial, the median progression-free survival was 15.2 months and the overall survival was 23.6 months. At the time of tumor recurrence, $91.6 \%$ of the tumors had lost EGFRvIII expression.

To date, the largest clinical trial using the PEPvIII-KLH vaccine enrolled 65 patients who were treated with the standard of care with surgical resection followed by 6 weeks of concurrent radiation and chemotherapy [61]. Prior to beginning maintenance therapy, all patients were given three vaccinations 2 weeks apart. During each 


\begin{tabular}{|c|c|c|c|c|c|}
\hline Study (year) & Patients (n) & Vaccine substrate & $\begin{array}{l}\text { Median overall } \\
\text { survival } \\
\text { (months) }\end{array}$ & Toxicity & Ref. \\
\hline $\begin{array}{l}\text { Sampson et al. } \\
\text { (2011) }\end{array}$ & 22 GBM & EGFRvIII & 23.6 & - & [23] \\
\hline $\begin{array}{l}\text { Sampson et al. } \\
\text { (2010) }\end{array}$ & $18 \mathrm{GBM}$ & EGFRvIII & 26 & $\begin{array}{l}\text { Grade } 2 \\
\text { injection-site } \\
\text { reaction }\end{array}$ & [24] \\
\hline $\begin{array}{l}\text { Sampson et al. } \\
\text { (2009) }\end{array}$ & - & EGFRvIll & - & - & [25] \\
\hline Choi et al. (2009) & - & EGFRvIII & - & - & [26] \\
\hline Lai et al. (2011) & 65 GBM & EGFRvIII & 24.6 & $\begin{array}{l}\text { Grade } 3 \text { epidermal } \\
\text { necrolysis } \\
\text { (1 patient) }\end{array}$ & [61] \\
\hline $\begin{array}{l}\text { Yajima et al. } \\
(2005)\end{array}$ & $25 \mathrm{HGG}$ & $\begin{array}{l}\text { Personalized peptide } \\
\text { vaccine }\end{array}$ & 20 & - & [62] \\
\hline $\begin{array}{l}\text { Crane et al. } \\
(2013)\end{array}$ & $12 \mathrm{GBM}$ & HSPPC & 11 & - & [63] \\
\hline $\begin{array}{l}\text { Steiner et al. } \\
\text { (2004) }\end{array}$ & 23 GBM & NDV & 23.5 & - & [30] \\
\hline $\begin{array}{l}\text { Okada et al. } \\
\text { (2007) }\end{array}$ & $6 \mathrm{HGG}$ & $\begin{array}{l}\text { IL-4 transfected } \\
\text { fibroblasts + autologous } \\
\text { glioma cells }\end{array}$ & - & $\begin{array}{l}\text { Grade } 1-2 \text { skin } \\
\text { reactions }\end{array}$ & [31] \\
\hline $\begin{array}{l}\text { Muragaki et al. } \\
\text { (2011) }\end{array}$ & $24 \mathrm{GBM}$ & AFTV & 21.4 & - & {$[28]$} \\
\hline $\begin{array}{l}\text { Sakamoto et al. } \\
\text { (2011) }\end{array}$ & 3 GBM & AFTV & - & - & [29] \\
\hline
\end{tabular}

28-day cycle of maintenance chemotherapy, patients received temozolomide on days 1-5 and then a booster vaccine on day 21 for up to 12 cycles, unless there was intolerance or disease progression. The vaccine was relatively well tolerated, although one patient experienced grade 3 toxic epidermal necrolysis. Some response to the vaccine was reported, with a median progressionfree survival of 12.3 months and overall survival of 24.6 months.

These promising trial data gave support for an ongoing Phase III, double-blind randomized controlled study of CDX-110 with adjuvant temozolomide in patients with newly diagnosed EGFRvIII-positive glioblastoma [101]. The primary outcome measure is overall survival. The study is being conducted at 100 centers with an estimated completion date of November 2016.

The advantage of a peptide-based vaccine such as CDX-110 is that the single peptide is relatively easy to mass produce and administer. The obvious disadvantage is that only a subset of glioblastoma tumors expresses this antigen. Furthermore, after vaccination at the time of recurrence, many tumors have lost EGFRvIII expression. This raises the question, would it be more advantageous to vaccinate with multiple antigens?

\section{Additional peptide-based vaccines}

In 2005, 25 patients with high-grade gliomas were evaluated in a Phase I clinical trial using a personalized peptide vaccine [62]. Cellular and humoral responses to 25 peptides in HLA-A24 ${ }^{+}$ patients and 23 peptides in HLA-A2 ${ }^{+}$patients were determined by IgG-specific antibodies to peptides in the plasma, the cytotoxic T-lymphocyte precursor assay, IFN- $\gamma$ production and delayed-type hypersensitivity responses. A maximum of four reactive peptides were used for in vivo administration. Cellular immune responses were observed in 14 out of 21 patients, and humoral immune responses were observed in 11 out of 21 patients. The median overall survival for patients with recurrent glioblastoma was 622 days ( 20 months), with five patients showing a partial clinical response to treatment.

Immunization with heat shock protein-peptide complexes (HSPPCs) is a novel approach to 
vaccination with multiple peptides [63]. HSPPCs are found in cancer cells and carry tumor-specific antigenic proteins. HSPPC-96 consists of a $96-\mathrm{kD}$ chaperone protein capable of binding antigenic proteins from glioblastoma. In a recent study, 12 patients with recurrent glioblastoma were vaccinated with HSPPC-96 derived from surgically resected tumor. The vaccination was well tolerated without any adverse events. The immune response measured in peripheral blood was based on IFN $\gamma$ production, peripheral blood leukocyte surface markers, a T-cell proliferation assay and intracellular cytokine staining. Significant antigen-specific immune responses were reported in 11 out of the 12 patients, who had a median survival of 47 weeks ( 11 months) compared with 16 weeks ( 4 months) for the single nonresponder.

Antigen-based vaccines may be derived from autologous tumor cells. The first human clinical trial for glioblastoma using autologous tumor cell vaccines was the 2001 trial of NDV described previously [27]. In a similar study, 23 patients were treated with up to eight intradermal injections of $1 \times 10^{7} \gamma$-irradiated autologous tumor cells transfected with NDV [30]. The vaccine was well tolerated and showed improvement in progression-free and overall survival compared with historical controls. In the vaccinated group, median progression-free survival was 40 weeks and overall survival was 100 weeks compared with 26 and 49 weeks, respectively, in the control patients.

In 2007, five patients with recurrent glioblastoma and one patient with anaplastic astrocytoma were enrolled in a study of autologous glioma cell vaccines admixed with IL-4 genetransfected fibroblasts [31]. IL-4 plays an important role in the maturation of DCs and promotes secretion of IL- 12 by DCs. Two of the six enrolled participants received the two planned vaccinations. The other four patients were withdrawn from the trial due to tumor progression prior to vaccination. As it took 7-8 weeks to generate sufficient numbers of IL-4-transfected fibroblasts, the trial was terminated early. In the two patients who received vaccines, grade 1 and 2 skin reactions were seen. The second part of the study recruited patients with newly diagnosed glioblastoma or anaplastic astrocytoma. Six patients were enrolled in the study and five received the two scheduled vaccinations. The treatment was well tolerated without any major adverse events. This arm of the study was not able to detect IFN- $\gamma$ postvaccine responses or changes in progression-free survival.

In 2011, two trials used an autologous formalin-fixed tumor vaccine given concomitantly with radiation therapy for newly diagnosed glioblastoma [28,29]. In these two studies, 27 patients were enrolled, 24 by Muragaki and colleagues [28], and three by the Sakamoto group [29]. In both trials, the autologous formalin-fixed tumor vaccine treatment consisted of three courses of five intradermal injections. The vaccine was well tolerated; treatment-related adverse effects included local erythema, induration, swelling and hematotoxicity. In the larger study, the median overall survival was 21.4 months and progression-free survival was 7.6 months [28].

\section{- Cell-based vaccines}

Based on the results of early clinical trials, cellbased vaccine therapy has also experienced recent interest. For most cell-based vaccines, DCs are prepared from autologous peripheral blood mononuclear cells and cultivated with growth factors and antigens. In total, 20 clinical trials have been published using DC vaccine therapies for glioblastoma (Table 3) [33-48,50,51,64,65]. A typical clinical trial design is illustrated in Figure 4, which incorporates vaccination into the standard-of-care treatment for gliomas. These trials have included 206 patients with newly diagnosed glioblastoma and 163 patients with recurrent glioblastoma. The trials have primarily used DCs pulsed with autologous tumor lysate, although there have been a handful of trials using DCs pulsed with eluted peptides or DC-tumor cell fusion vaccines. Administration has been mostly intradermal, with the exception of two studies that included intratumoral injection, one study that used subcutaneous injection and a study from our institution that vaccinated by injection into the cervical lymph nodes. In general, autologous DC therapy has been remarkably well tolerated. The grade 3 and 4 toxicities related to the vaccine have been minimal, including two reports of peritumoral edema and one report of a cutaneous glioblastoma forming at the inoculation site for delayed-type hypersensitivity testing. Some studies have shown clinical responses, either in tumor regression based on imaging or improved survival compared with historical or contemporary controls. Immune responses have also been demonstrated with the use of surrogate end points. Monitoring immune responses to $\mathrm{DC}$ vaccines is challenging because the antigens 


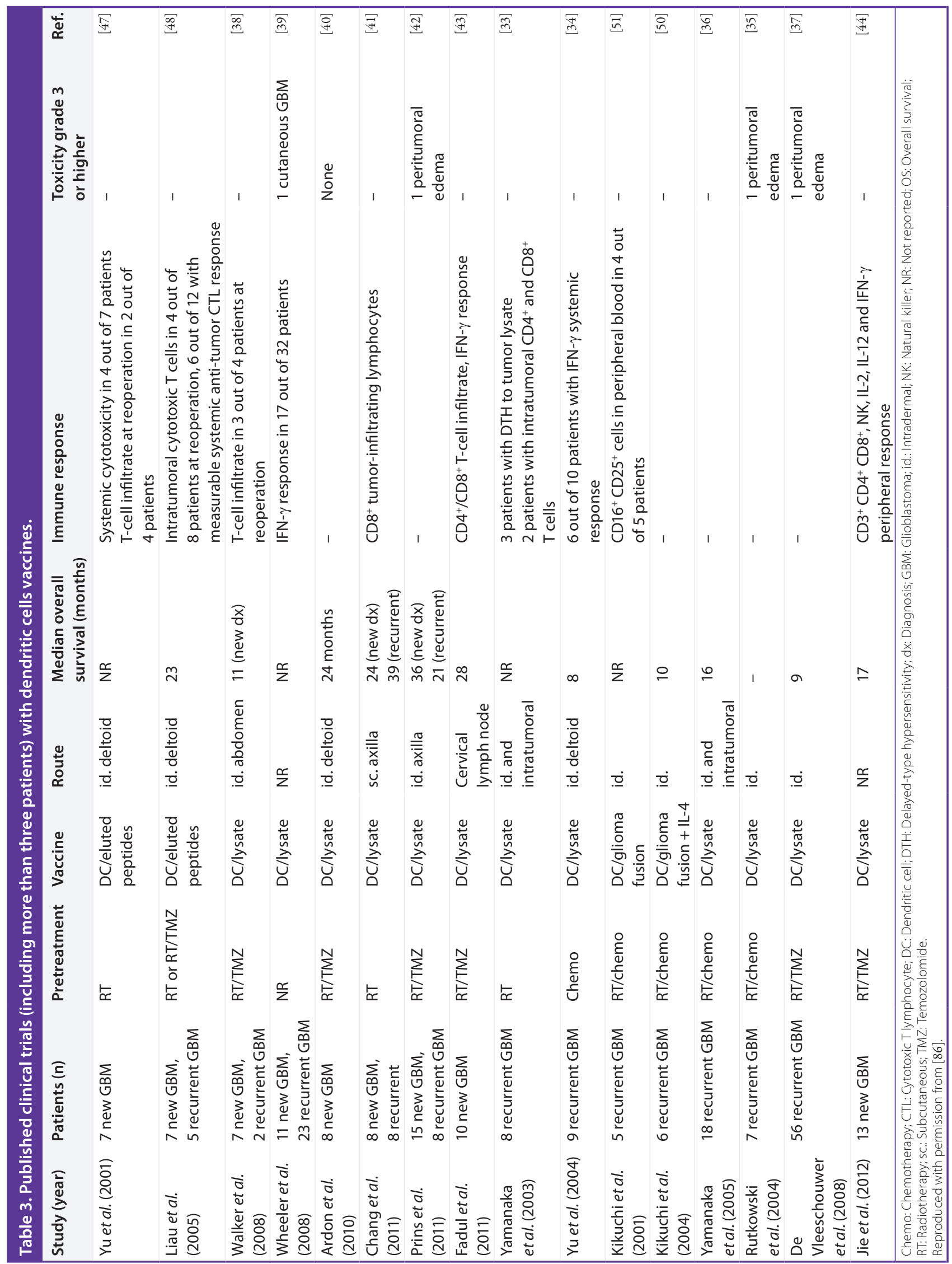




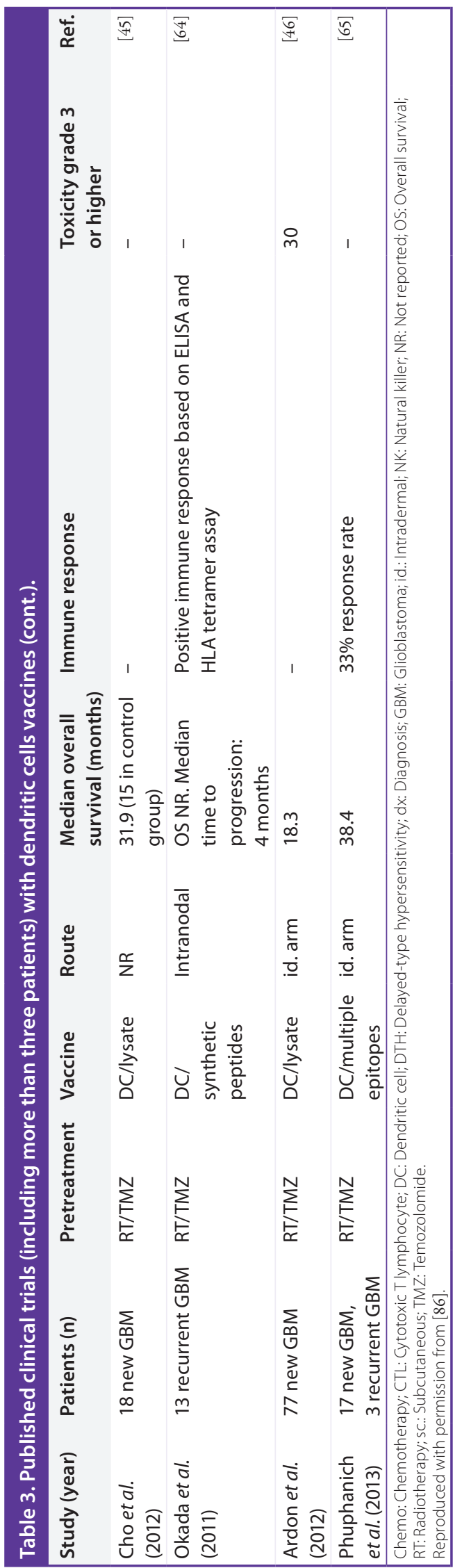




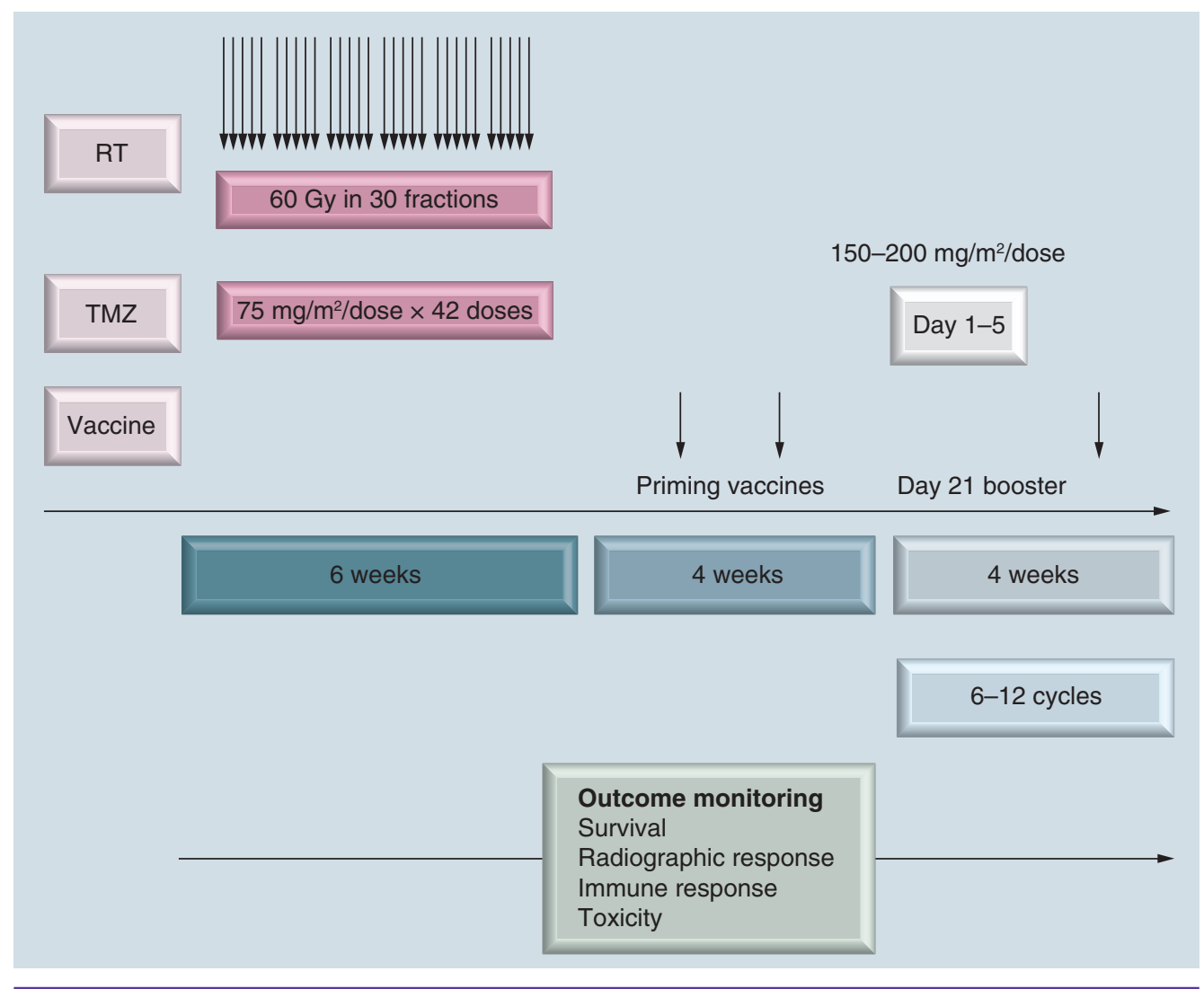

Figure 4. Typical clinical trial design. It remains to be determined how vaccination should best fit in with the standard-of-care treatment for glioblastoma. In most clinical trials, the patient undergoes surgery for diagnosis and to acquire tissue. While the vaccine is prepared from the harvested tissue, the patient undergoes concomitant radiation and chemotherapy. A series of vaccinations is then given, followed by maintenance chemotherapy. Patients are monitored for clinical, radiographic and immune responses to treatment.

RT: Radiotherapy; TMZ: Temozolomide.

are often undefined, as with DCs pulsed with autologous tumor lysate. In such cases, the antigen-specific immune response cannot be monitored. General measures of immune activation such as T-cell profiles or cytokine concentrations are often used as surrogate markers of immune response.

Two trials with cell-based vaccines must be noted, as they were able to demonstrate vaccine responses in a randomized setting, although neither was blinded for the treatment arm. In one study, patients with newly diagnosed glioblastoma were randomly assigned to a control group who received the standard of care (surgery, radiation and chemotherapy), or the vaccine group who received standard of care plus DC vaccination immunotherapy [44]. Twenty five patients were included in the study, 13 in the DC vaccination group and 12 in the control group. The DC vaccine group received four subcutaneous injections of $6 \times 10^{6}$ mature DCs loaded with heat shock-treated autologous tumor cells as the antigen source. The immune response, measured by proportions of peripheral $\mathrm{CD}^{+}, \mathrm{CD}^{+}$, the $\mathrm{CD}^{+}$: $\mathrm{CD}^{+}$ratio and natural killer cells, was significantly higher in the DC vaccination group compared with controls, as were serum concentrations of IL-2, IL-12 and IFN- $\gamma$. In another Phase II clinical trial, patients with newly diagnosed glioblastoma were again randomized to standard therapy (16 patients) versus standard therapy plus vaccination with whole-tumor lysate-loaded DCs (18 patients) [45]. The median overall survival for the vaccine group was 31.9 versus 15 months for the control group, and progression-free survival was 8.5 versus 8 months, respectively.

Human cytomegalovirus (CMV) is another potential therapeutic target for vaccine therapy. CMV is expressed in many gliomas [66], and 
may play a role in oncomodulation to a malignant phenotype [67]. In 2008, a patient with glioblastoma treated with a DC vaccine pulsed with an autologous tumor lysate exhibited an immune response to CMV [68]. As CMV proteins and oligonucleotides are expressed by glioma tissue, vaccinations using CMV antigens may target glioblastoma cells. CMV proteins are not expressed in surrounding nontumor brain tissue $[66,69]$. In a Phase I/II trial of an autologous DC vaccine pulsed with CMV peptides, patients with newly diagnosed glioblastoma had a median survival of 21 months [70].

A recent Phase I clinical trial reported the immune responses to vaccination with six tumor-associated antigen epitopes, including HER2, TRP-2, gp100, MAGE-1, IL-13R $\alpha 2$ and AIM-2, collectively referred to as ICT107 [65]. Twenty one patients were enrolled, 17 with newly diagnosed glioblastoma, three with recurrent glioblastoma and one with a brainstem glioma. All patients' tumors expressed at least three of the tumor-associated antigen epitopes and $75 \%$ of the patients expressed all six antigens. Among the 15 newly diagnosed patients treated, the median progression-free survival was 16.9 months and overall survival was 38.4 months; $33 \%$ of the patients were considered immune responders based on antigenspecific responses determined by functional assays measuring proportions of $\mathrm{CD}^{+}$cells and IFN- $\gamma$ responses.

Results of a recent clinical trial at our institution provided support for the use of a vaccine strategy in treating glioblastoma [43]. In this trial, ten patients with newly diagnosed glioblastoma were vaccinated with ultrasound-guided intranodal injections of $1 \times 10^{7}$ autologous tumor lysate-loaded DCs. Evaluable patients received one vaccination every 2 weeks on three occasions after concomitant radiation and temozolomide chemotherapy but prior to maintenance chemotherapy. The median progression-free survival was 9.5 months and the median overall survival was 28 months. The vaccine elicited an immune response to the autologous tumor that correlated with clinical outcome. Vaccines were well tolerated with one grade 2 adverse event, unilateral neck pain, after one cervical lymph node vaccine injection. When patients were dichotomized into two groups, based on results of correlative immune measures of specific antitumor response to vaccination, the group with a higher immune index correlated with the highest overall survival. This may indicate that a certain immune function 'threshold' is needed to respond positively to tumor-specific vaccination.

To date, the largest clinical trial using cellbased vaccines was the HGG-2006 trial, a Phase I/II trial of autologous DC-based vaccines for treating patients with newly diagnosed glioblastoma [46]. Seventy seven patients were enrolled in the trial, all of whom underwent surgery and were removed from steroids at the time of leukapheresis and at the time of vaccination. These 77 patients were treated with standard-ofcare radiation therapy and concomitant temozolomide, followed by four-weekly intradermal vaccinations of autologous tumor-loaded DCs. Patients continued on treatment to complete monthly cycles of temozolomide and received booster vaccinations 1 week after the first, second, third and sixth cycles of chemotherapy, and longer if enough lysate was available. The treatment was well tolerated. The 6-month progression-free survival was $70.1 \%$ with an overall survival of 18.3 months.

Taken together, these Phase I and II clinical trial data confirm that cell-based vaccine studies are feasible, safe and induce immune responses. The promising results in progression-free and overall survival provide strong support for Phase III clinical trials to compare vaccine therapy with the standard of care. DCVax ${ }^{\circledR}$ (Northwest Biotherapeutics, MD, USA) is an ongoing Phase III clinical trial of an autologous DC vaccine pulsed with autologous tumor lysate or placebo for treating newly diagnosed glioblastoma [102]. The patients receive standard-of-care surgery followed by concomitant radiation and chemotherapy prior to vaccine administration. For every three patients enrolled in the trial, two will receive $\mathrm{DC}$ vaccines, while one will be given placebo. The primary outcome is progressionfree survival and secondary outcome compares overall survival between the two groups. This study began enrollment in December 2006. The estimated completion date for the primary outcome measure is June 2013, although accrual had been slow at the time of writing.

Despite these successes, there are significant limitations to the development of cell-based vaccines. One limitation lies in the report of outcomes. Early clinical trials for DC vaccines are often not powered or designed to determine a survival advantage, so surrogate measures of immune response are used to reflect the efficacy of the vaccine. None of the T-cell-based 
immune response measures have been universally validated, making it difficult to compare trials and even to interpret some trial results [71]. The apparent advantage of DC vaccines is their tolerability and low side-effect profile; however, the lack of autoimmunity may reflect an insufficient immune response for tumor eradication [71]. In addition, determining the ideal dose is difficult. Unlike traditional pharmaceutical trials that use dose escalation paradigms in their early-phase studies, the dose of DC vaccines is limited both by the amount of tumor lysate available and by the number of DCs that are prepared from peripheral blood [71]. In an era of personalized medicine, autologous tumor vaccination, whether antigen- or cell-based, offers an individualized tumor-specific approach to treatment. However, such an approach is both labor intensive and expensive, which places limits on the scale of a clinical trial. Vaccination is not feasible for all patients, nor is it effective in all patients. For vaccination to be effective, patients must be able to mount an immune response. The ideal patient is one who has undergone gross total resection with minimal residual tumor, is not receiving steroids and has a functional immune reserve. The glioblastoma subtype and the balance of regulatory and effector immune cells may also affect the response to vaccination.

Future directions: optimizing vaccines

Glioblastoma is expert at immune evasion. It is located behind the blood-brain barrier, secretes immunosuppressive cytokines and alters the careful balance between immune activation and immune regulation to favor an overall immunosuppressed state in its host. However, it is promising that vaccine therapeutic strategies are still able to stimulate an immune response. Careful manipulation of the immune system may induce a more robust response. Part of the approach to further optimize vaccines may include fine-tuning several potential targets.

Our immune system consists of a series of checks and balances designed to prevent overactivation of the immune system and autoimmunity. The immune system contains both effector cells and regulatory cells. Tregs play a key role in immune regulation and tumor tolerance [72]. Activated T cells upregulate two important cell membrane proteins: CTLA-4 and PD-1. For a cytotoxic $\mathrm{CD}^{+} \mathrm{T}$ cell to be activated, it not only has to recognize an antigen presented on a MHC, but also has to have a second signal.
The second signal is initiated by the binding of the costimulatory cell-surface marker CD28 to its ligand, B7. CTLA-4 competes with CD28 for binding to $\mathrm{B} 7$. PD-1, on the other hand, has its own ligand, PD-L1. Binding of CTLA-4 to B7 or binding of PD-1 to PD-L1 will downregulate $\mathrm{CD}^{+}$cytotoxic T cells. CLTA- 4 is also expressed on the surface of Tregs [73]. Tregs have been demonstrated to have inhibitory effects on $\mathrm{CD}^{+}$ $\mathrm{T}$ cells, CD4 ${ }^{+} \mathrm{T}$ cells, DCs and natural killer cells, thus dampening the immune response.

The clinical relevance of these immune checkpoints is thus far best illustrated in the treatment of metastatic melanoma. Ipilimumab, a human monoclonal antibody against CTLA-4, has been approved for the treatment of metastatic melanoma based on the results of two randomized clinical trials, both of which demonstrated a significant improvement in overall survival [74,75]. Presumably, blocking CTLA-4 with ipilimumab allows for a more robust antitumor T-cell response to the melanoma and has also been useful in treating melanoma brain metastases [76].

In glioblastoma, the frequency of Tregs in peripheral blood, as well as CTLA-4 expression on T cells, may predict patient responses to DC vaccines [77]. Immune regulation was studied in a Phase I trial with a group of 24 patients treated with DC vaccines. A decrease in Treg frequency after DC vaccination correlated with increased survival. Furthermore, expression of CTLA-4 on the Tregs was also significantly associated with survival. A similar correlation was observed in patients with glioblastoma who were not treated with vaccines. In a population of 65 patients with glioblastoma, poorer survival correlated with higher levels of tumor-infiltrating $\mathrm{T}$ cells and Tregs as measured by a DNA demethylation assay [22].

These observations suggest strategies to exploit the intrinsic mechanisms of immune regulation that optimize response to vaccine therapy. Daclizumab is a humanized monoclonal antibody that binds to the high-affinity IL-2 receptor, thereby blocking IL-2 binding. The high-affinity IL-2R $\alpha$ is constitutively expressed on Tregs, and blocking it with daclizumab should selectively reduce Tregs. One strategy to increase immune response may be to deplete Tregs. In a pilot study of patients with glioblastoma, daclizumab was given at the time of EGFRvIII peptide vaccination to selectively deplete peripheral blood Tregs [78]. Six patients 
with newly diagnosed EGFRvIII-expressing glioblastoma were enrolled in the pilot study. All were treated with standard-of-care radiation with concomitant temozolomide and then randomized to receive either saline or a single dose of daclizumab along with the PEPvIII peptide vaccine. The accrual goal of 20 patients was not reached due to discontinuation of daclizumab by the manufacturer. The daclizumab-treated patients had significantly reduced circulating Tregs. Furthermore, the frequency of Tregs was inversely correlated with the concentration of EGFRvIII-specific humoral immune responses.

Another small study reported combining DC vaccination with a TLR agonist, an alternative approach to boost vaccine immune response by activating peripheral effector cells [42]. Twenty three enrolled patients with glioblastoma received standard-of-care chemotherapy and radiation therapy, followed by vaccination with autologous DCs pulsed with tumor lysate. In addition to the vaccination, patients were given a TLR agonist: either imiquimod or a synthetic complex of carboxymethylcellulose, polyinosinic-polycytidylic acid and poly--Llysine dsRNA. The combination treatment was well tolerated and the median overall survival was 31.4 months. Because this was an early-phase dose escalation trial, there was no control group to determine whether the TLR agonist improved the immune response, but the encouraging safety profile provides support for further trials.

Manipulation of the PTEN pathway may be another way to improve the immune response to vaccine therapy. PTEN is a tumor suppressor gene that is frequently lost in glioblastoma [79-81]. Tumors that have lost PTEN expression increase expression of the $\mathrm{B} 7-\mathrm{H} 1$ protein, which leads to increased immune resistance [82], an effect dependent on the PI3K pathway. B7-H1 protein expression is regulated post-transcriptionally in gliomas that have lost PTEN. Expression of B7-H1 can be increased with the addition of IFN- $\gamma$ to PTENdeficient glioblastoma cell lines [83]. When IFN$\gamma$-treated glioblastoma cells are co-cultured with autologous lymphocytes and $\mathrm{T}$ cells, the lymphocytes and $\mathrm{T}$ cells undergo apoptosis resulting in an extremely immunoresistant glioblastoma cell line. This is probably a mechanism of immune escape for glioblastoma, as studies of human tissue show similar findings to cell culture lines [84]. When human PTEN wild-type tumors are compared with PTEN-deficient tumors, they induce significantly greater T-cell apoptosis. This implies that tumors with loss of PTEN may be poor targets for immunotherapy. However, if the PTEN/PI3K/B7-H1 pathway can be targeted, this may be a way to optimize vaccine therapy in future trials.

TGF- $\beta 2$ may be another target to increase the response to vaccine therapy [48]. In 2005, a small trial of 12 patients enrolled in a dose-escalation study of an autologous DC vaccine; six patients had measureable systemic anti-tumor cytotoxic T-lymphocyte responses. Among eight patients who underwent reoperation after vaccination, four had increased intratumoral infiltration by cytotoxic T cells, and the magnitude of T-cell infiltration was inversely correlated with TGF$\beta 2$ tumor expression and positively correlated with survival. This suggests that gliomas with low TGF- $\beta 2$ expression may respond better to vaccine therapy. TGF- $\beta 2$ expression may be a targetable biomarker of immune response.

\section{Conclusion \& future perspective}

If the ongoing Phase III clinical trials with both peptide- and DC-based vaccines demonstrate a clinical benefit, we can gain valuable insights to help design the optimal schedule and approach of vaccination combined with the current standard treatment scheme for glioblastoma. Although we know that radiation and temozolomide induces lymphopenia, what remains to be determined is when vaccination would be most effective in the treatment paradigm, either prior to radiation therapy to prime an immune response or after concomitant therapy to boost an impaired immune system. There may be a synergistic effect from giving chemotherapy with vaccination. One retrospective study reported that combined vaccination and chemotherapy correlated with significantly longer postchemotherapy recurrence times and longer survival compared with vaccination or chemotherapy alone, suggesting a synergistic clinical benefit from combined therapy [85]. A study with the EGFRvIII peptide vaccine showed that the humoral and delayed-type hypersensitivity responses were of greater magnitude in patients receiving doseintensified temozolomide compared with the standard dose [23].

Another important treatment question is whether there is the need for maintenance of booster vaccinations after the initial induction of the immune response. The roles that patient and tumor characteristics play in predicting response to immunotherapy must be considered. In a study 
of 12 patients treated with autologous DC vaccines, the absence of bulky, actively progressing tumor and low TGF- $\beta 2$ expression correlated positively with survival [48]. This study group reported that tumors with the mesenchymal gene expression profile may identify a group of patients who are more responsive to immune-based therapies [42]. Maximal vaccine effectiveness is dependent upon many variables: individual patient characteristics, the tumor and its microenvironment, as well as integration with other therapies. The future of this novel treatment modality appears promising. Incorporating vaccine therapy as part of the standard of care for patients with glioblastoma will depend on the results of ongoing clinical trials, an increased understanding of the modulators of the immune system, and identification of biomarkers that predict the patients who may benefit most from immunotherapy.

In 2005, the concomitant use of radiation and chemotherapy improved survival in patients with glioblastoma from 12 to 14.6 months [2]. This is the last major advance in the treatment of a disease that still has a dismal prognosis. Over 10 years of preclinical and early clinical trials in vaccine therapy have demonstrated a safe, well-tolerated and potentially effective treatment modality. Although treating an immunosuppressive tumor with immunotherapy remains challenging, the personalized nature of autologous vaccination has potentially great rewards. With Phase III clinical trials underway, we will soon know if these vaccine therapies will improve survival in glioblastoma. More complex immunotherapy regimens, which include multiple agents combining several approaches to enhance immune activation and decrease immune suppression/regulation, are on the horizon. As we improve our understanding of neuroimmunology, regulatory pathways and biomarkers for vaccine response, we may be able to target costimulatory and immunosuppressive molecules to optimize this promising treatment modality and significantly improve the outcome for patients with glioblastoma.

\section{Acknowledgements}

The authors would like to express their gratitude to C Dant for his critical review of the manuscript and to M Robinson for her editorial assistance.

\section{Financial \& competing interests disclosure}

The authors have no relevant affiliations or financial involvement with any organization or entity with a financial interest in or financial conflict with the subject matter or materials discussed in the manuscript. This includes employment, consultancies, honoraria, stock ownership or options, expert testimony, grants or patents received or pending, or royalties.

No writing assistance was utilized in the production of this manuscript.

\section{References}

Papers of special note have been highlighted as: of interest

- of considerable interest

1 Surawicz TS, McCarthy BJ, Kupelian V et al. Descriptive epidemiology of primary brain and CNS tumors: results from the Central Brain Tumor Registry of the United States, 1990-1994. Neuro Oncol. 1(1), 14-25 (1999).

2 Stupp R, Mason WP, van den Bent MJ et al. Radiotherapy plus concomitant and adjuvant temozolomide for glioblastoma. N. Engl. J. Med. 352(10), 987-996 (2005).

3 Kreisl TN, Kim L, Moore K et al. Phase II trial of single-agent bevacizumab followed by bevacizumab plus irinotecan at tumor progression in recurrent glioblastoma. J. Clin Oncol. 27(5), 740-745 (2009).

4 Friedman HS, Prados MD, Wen PY et al. Bevacizumab alone and in combination with irinotecan in recurrent glioblastoma. J. Clin. Oncol. 27(28), 4733-4740 (2009).
5 Hegi ME, Diserens AC, Gorlia T et al. $M G M T$ gene silencing and benefit from temozolomide in glioblastoma. N. Engl. J. Med. 352(10), 997-1003 (2005).

6 Stupp R, Hegi ME, Mason WP et al. Effects of radiotherapy with concomitant and adjuvant temozolomide versus radiotherapy alone on survival in glioblastoma in a randomised Phase III study: 5-year analysis of the EORTC-NCIC trial. Lancet Oncol. 10(5), 459-466 (2009)

7 Donson AM, Birks DK, Schittone SA et al. Increased immune gene expression and immune cell infiltration in high-grade astrocytoma distinguish long-term from short-term survivors. J. Immunol. 189(4), 1920-1927 (2012).

8 Charles NA, Holland EC, Gilbertson R, Glass R, Kettenmann H. The brain tumor microenvironment. Glia 60(3), 502-514 (2012).
9 Jaeckle KA. Immunotherapy of malignant gliomas. Semin. Oncol. 21(2), 249-259 (1994).

10 Gomez GG, Kruse CA. Mechanisms of malignant glioma immune resistance and sources of immunosuppression. Gene Ther. Mol. Biol. 10(A), 133-146 (2006).

11 Weller M, Fontana A. The failure of current immunotherapy for malignant glioma. Tumor-derived TGF-beta, T-cell apoptosis, and the immune privilege of the brain. Brain Res. Rev. 21(2), 128-151 (1995).

12 Hayes RL, Arbit E, Odaimi M et al. Adoptive cellular immunotherapy for the treatment of malignant gliomas. Crit. Rev. Oncol. Hematol. 39(1-2), 31-42 (2001).

13 Sankhla SK, Nadkarni JS, Bhagwati SN. Adoptive immunotherapy using lymphokineactivated killer (LAK) cells and interleukin-2 for recurrent malignant primary brain tumors. J. Neurooncol. 27(2), 133-140 (1996). 
14 Hickey WF, Hsu BL, Kimura H. T-lymphocyte entry into the central nervous system. J. Neurosci. Res. 28(2), 254-260 (1991).

15 Tambuyzer BR, Ponsaerts P, Nouwen EJ. Microglia: gatekeepers of central nervous system immunology. J. Leukoc. Biol. 85(3), 352-370 (2009).

16 Roszman T, Elliott L, Brooks W. Modulation of T-cell function by gliomas. Immunol. Today 12(10), 370-374 (1991).

17 Elliott LH, Brooks WH, Roszman TL. Activation of immunoregulatory lymphocytes obtained from patients with malignant gliomas. J. Neurosurg. 67(2), 231-236 (1987).

18 Fecci PE, Mitchell DA, Whitesides JF et al. Increased regulatory $\mathrm{T}$-cell fraction amidst a diminished CD4 compartment explains cellular immune defects in patients with malignant glioma. Cancer Res. 66(6), 3294-3302 (2006).

19 Fadul CE, Fisher JL, Gui J, Hampton TH, Cote AL, Ernstoff MS. Immune modulation effects of concomitant temozolomide and radiation therapy on peripheral blood mononuclear cells in patients with glioblastoma multiforme. Neuro Oncol. 13(4), 393-400 (2011).

20 Grossman SA, Ye X, Lesser G et al. Immunosuppression in patients with high-grade gliomas treated with radiation and temozolomide. Clin. Cancer Res. 17(16), 5473-5480 (2011).

21 Lohr J, Ratliff T, Huppertz A et al. Effector T-cell infiltration positively impacts survival of glioblastoma patients and is impaired by tumor-derived TGF-beta. Clin. Cancer Res. 17(13), 4296-4308 (2011).

22 Wiencke JK, Accomando WP, Zheng S et al. Epigenetic biomarkers of T-cells in human glioma. Epigenetics 7(12), 1391-1402 (2012).

23 Sampson JH, Aldape KD, Archer GE et al. Greater chemotherapy-induced lymphopenia enhances tumor-specific immune responses that eliminate EGFRvIII-expressing tumor cells in patients with glioblastoma. Neuro Oncol. 13(3), 324-333 (2011).

24 Sampson JH, Heimberger AB, Archer GE et al. Immunologic escape after prolonged progression-free survival with epidermal growth factor receptor variant III peptide vaccination in patients with newly diagnosed glioblastoma. J. Clin. Oncol. 28(31), 4722-4729 (2010).

- First paper to show the role of immune evasion in vaccine therapy.

25 Sampson JH, Archer GE, Mitchell DA et al. An epidermal growth factor receptor variant III-targeted vaccine is safe and immunogenic in patients with glioblastoma multiforme. Mol. Cancer Ther. 8(10), 2773-2779 (2009).

26 Choi BD, Archer GE, Mitchell DA et al. EGFRvIII-targeted vaccination therapy of malignant glioma. Brain Pathol. 19(4), 713-723 (2009).

27 Schneider T, Gerhards R, Kirches E, Firsching R. Preliminary results of active specific immunization with modified tumor cell vaccine in glioblastoma multiforme. J. Neurooncol. 53(1), 39-46 (2001).

28 Muragaki Y, Maruyama T, Iseki H et al. Phase I/IIa trial of autologous formalin-fixed tumor vaccine concomitant with fractionated radiotherapy for newly diagnosed glioblastoma. Clinical article. J. Neurosurg. 115(2), 248-255 (2011).

- Among the first randomized trials for vaccine therapy.

29 Sakamoto N, Ishikawa E, Yamamoto T et al. Pathological changes after autologous formalin-fixed tumor vaccine therapy combined with temozolomide for glioblastoma - three case reports. Neurol. Med. Chir. (Tokyo) 51(4), 319-325 (2011).

- Small randomized trial for vaccine therapy.

30 Steiner HH, Bonsanto MM, Beckhove P et al. Antitumor vaccination of patients with glioblastoma multiforme: a pilot study to assess feasibility, safety, and clinical benefit. J. Clin. Oncol. 22(21), 4272-4281 (2004).

31 Okada H, Lieberman FS, Walter KA et al. Autologous glioma cell vaccine admixed with interleukin- 4 gene transfected fibroblasts in the treatment of patients with malignant gliomas. J. Transl. Med. 5, 67 (2007).

32 Vauleon E, Avril T, Collet B, Mosser J, Quillien V. Overview of cellular immunotherapy for patients with glioblastoma. Clin. Dev. Immunol. 2010, 1-19 (2010).

33 Yamanaka R, Abe T, Yajima $\mathrm{N}$ et al. Vaccination of recurrent glioma patients with tumour lysate-pulsed dendritic cells elicits immune responses: results of a clinical Phase I/II trial. Br. J. Cancer 89(7), 1172-1179 (2003).

34 Yu JS, Liu G, Ying H, Yong WH, Black KL, Wheeler CJ. Vaccination with tumor lysate-pulsed dendritic cells elicits antigenspecific, cytotoxic T-cells in patients with malignant glioma. Cancer Res. 64(14), 4973-4979 (2004).

35 Rutkowski S, De Vleeschouwer S, Kaempgen E et al. Surgery and adjuvant dendritic cell-based tumour vaccination for patients with relapsed malignant glioma, a feasibility study. Br. J. Cancer 91(9), 1656-1662 (2004).

36 Yamanaka R, Homma J, Yajima $\mathrm{N}$ et al. Clinical evaluation of dendritic cell vaccination for patients with recurrent glioma: results of a clinical Phase I/II trial. Clin. Cancer Res. 11(11), 4160-4167 (2005).

37 De Vleeschouwer S, Fieuws S, Rutkowski S et al. Postoperative adjuvant dendritic cell-based immunotherapy in patients with relapsed glioblastoma multiforme. Clin. Cancer Res. 14(10), 3098-3104 (2008).

38 Walker DG, Laherty R, Tomlinson FH, Chuah T, Schmidt C. Results of a Phase I dendritic cell vaccine trial for malignant astrocytoma: potential interaction with adjuvant chemotherapy. J. Clin. Neurosci. 15(2), 114-121 (2008).

39 Wheeler CJ, Black KL, Liu G et al. Vaccination elicits correlated immune and clinical responses in glioblastoma multiforme patients. Cancer Res. 68(14), 5955-5964 (2008).

40 Ardon H, van Gool S, Lopes IS et al. Integration of autologous dendritic cell-based immunotherapy in the primary treatment for patients with newly diagnosed glioblastoma multiforme: a pilot study. J. Neurooncol. 99(2), 261-272 (2010).

41 Chang CN, Huang YC, Yang DM et al. A Phase I/II clinical trial investigating the adverse and therapeutic effects of a postoperative autologous dendritic cell tumor vaccine in patients with malignant glioma. J. Clin. Neurosci. 18(8), 1048-1054 (2011).

42 Prins RM, Soto H, Konkankit V et al. Gene expression profile correlates with $\mathrm{T}$-cell infiltration and relative survival in glioblastoma patients vaccinated with dendritic cell immunotherapy. Clin. Cancer Res. 17(6), 1603-1615 (2011).

43 Fadul CE, Fisher JL, Hampton TH et al. Immune response in patients with newly diagnosed glioblastoma multiforme treated with intranodal autologous tumor lysate-dendritic cell vaccination after radiation chemotherapy. J. Immunother. 34(4), 382-389 (2011).

44 Jie X, Hua L, Jiang W, Feng F, Feng G, Hua Z. Clinical application of a dendritic cell vaccine raised against heat-shocked glioblastoma. Cell. Biochem. Biophys. 62(1), 91-99 (2012).

45 Cho DY, Yang WK, Lee HC et al. Adjuvant immunotherapy with whole-cell lysate dendritic cells vaccine for glioblastoma multiforme: a Phase II clinical trial. World Neurosurg. 77(5-6), 736-744 (2012). 
46 Ardon H, Van Gool SW, Verschuere T et al. Integration of autologous dendritic cell-based immunotherapy in the standard of care treatment for patients with newly diagnosed glioblastoma: results of the HGG-2006 Phase I/II trial. Cancer Immunol. Immunother. 61(11), 2033-2044 (2012).

-1- Largest clinical trial to date using dendritic cell vaccine therapy in glioblastoma.

$47 \mathrm{Yu}$ JS, Wheeler CJ, Zeltzer PM et al. Vaccination of malignant glioma patients with peptide-pulsed dendritic cells elicits systemic cytotoxicity and intracranial T-cell infiltration. Cancer Res. 61(3), 842-847 (2001).

48 Liau LM, Prins RM, Kiertscher SM et al. Dendritic cell vaccination in glioblastoma patients induces systemic and intracranial T-cell responses modulated by the local central nervous system tumor microenvironment. Clin. Cancer Res. 11(15), 5515-5525 (2005).

49 Zhang Z, Tang LL, Zhan RY, Tong Y, Yao HP, Du LA. Immunotherapy of intracranial G422 glioblastoma with dendritic cells pulsed with tumor extract or RNA. J. Zhejiang Uni. Sci. 5(10), 1298-1303 (2004).

50 Kikuchi T, Akasaki Y, Abe T et al. Vaccination of glioma patients with fusions of dendritic and glioma cells and recombinant human interleukin 12. J. Immunother. 27(6), 452-459 (2004).

51 Kikuchi T, Akasaki Y, Irie M, Homma S, Abe T, Ohno T. Results of a Phase I clinical trial of vaccination of glioma patients with fusions of dendritic and glioma cells. Cancer Immunol. Immunother. 50(7), 337-344 (2001).

52 Nauts HC, McLaren JR. Coley toxins - the first century. Adv. Exp. Med. Biol. 267, 483-500 (1990).

53 De Bonis P, Albanese A, Lofrese G et al. Postoperative infection may influence survival in patients with glioblastoma: simply a myth? Glioblastoma, infection and survival. Neurosurgery 69(4), 864-869 (2011).

54 Dillman RO. Cancer immunotherapy. Cancer Biother. Radiopharm. 26(1), 1-64 (2011).

55 Bergquist BJ, Mahaley MS Jr, Steinbok P, Dudka L. Treatment of a brain tumor with BCG cell wall preparation. Surg. Neurol. 13(3), 197-201 (1980).

56 Mahaley MS Jr, Bigner DD, Dudka LF et al. Immunobiology of primary intracranial tumors. Part 7: active immunization of patients with anaplastic human glioma cells: a pilot study. J. Neurosurg. 59(2), 201-207 (1983).
57 Mittelman A, Urban R, Wong G, Ahmed T, Arlin Z. Phase I trial of ImuVert (natural membrane vesicles associated with ribosomes) in patients with advanced cancer. Cancer Immunol. Immunother. 35(5), 331-334 (1992).

58 Jaeckle KA, Mittelman A, Hill FH. Phase II trial of Serratia marcescens extract in recurrent malignant astrocytoma. J. Clin. Oncol. 8(8), 1408-1418 (1990).

59 Black KL, Ciacci JD, Ammirati M, Selch MT, Becker DP. Clinical trial of Serratia marcescens extract and radiation therapy in patients with malignant astrocytoma. J. Clin. Oncol. 11(9), 1746-1750 (1993).

60 Csatary LK, Bakacs T. Use of Newcastle disease virus vaccine $(\mathrm{MTH}-68 / \mathrm{H})$ in a patient with high-grade glioblastoma. JAMA 281(17), 1588-1589 (1999).

61 Lai RK, Recht LD, Reardon DA et al. Longterm follow-up of Act III: a Phase II trial of rindopepimut (Cdx-110) in newly diagnosed glioblastoma. Neuro Oncol. 13, 34 (2011).

- Although only in abstract form, this is the largest clinical trial to date of the EGFRvIII vaccine.

62 Yajima N, Yamanaka R, Mine T et al. Immunologic evaluation of personalized peptide vaccination for patients with advanced malignant glioma. Clin. Cancer Res. 11(16), 5900-5911 (2005).

63 Crane CA, Han SJ, Ahn B et al. Individual patient-specific immunity against high-grade glioma after vaccination with autologous tumor derived peptides bound to the $96 \mathrm{KD}$ chaperone protein. Clin. Cancer Res. 19(1), 205-214 (2013).

- Novel approach to vaccine therapy and avoids the need for isolating dendritic cells.

64 Okada H, Kalinski P, Ueda R et al. Induction of $\mathrm{CD}^{+}{ }^{+} \mathrm{T}$-cell responses against novel gliomaassociated antigen peptides and clinical activity by vaccinations with \{alpha\}-type 1 polarized dendritic cells and polyinosinicpolycytidylic acid stabilized by lysine and carboxymethylcellulose in patients with recurrent malignant glioma. J. Clin. Oncol. 29(3), 330-336 (2011).

65 Phuphanich S, Wheeler CJ, Rudnick JD et al. Phase I trial of a multi-epitope-pulsed dendritic cell vaccine for patients with newly diagnosed glioblastoma. Cancer Immunol. Immunother. 62(1), 125-135 (2013).

66 Cobbs CS, Harkins L, Samanta M et al. Human cytomegalovirus infection and expression in human malignant glioma. Cancer Res. 62(12), 3347-3350 (2002).

67 Dziurzynski K, Chang SM, Heimberger AB et al. Consensus on the role of human cytomegalovirus in glioblastoma. Neuro Oncol. 14(3), 246-255 (2012).

68 Prins RM, Cloughesy TF, Liau LM. Cytomegalovirus immunity after vaccination with autologous glioblastoma lysate. $N$. Engl. J. Med. 359(5), 539-541 (2008).

69 Sampson JH, Mitchell DA. Is cytomegalovirus a therapeutic target in glioblastoma? Clin. Cancer Res. 17(14), 4619-4621 (2011).

70 Mitchell DA, Archer G, Bigner D et al. Dendritic cell vaccines targeting human cytomegalovirus in glioblastoma reveal lymph node homing as a major axis for clinical intervention. Neuro Oncol. 14, 47-47 (2012).

71 Heimberger AB, Sampson JH. Immunotherapy coming of age: what will it take to make it standard of care for glioblastoma? Neuro Oncol. 13(1), 3-13 (2011).

- Nice review with interesting insights into the future of vaccine therapy.

72 Sakaguchi S, Sakaguchi N, Asano M, Itoh M, Toda M. Immunologic self-tolerance maintained by activated $T$ cells expressing IL-2 receptor alpha-chains (CD25). Breakdown of a single mechanism of self-tolerance causes various autoimmune diseases. J. Immunol. 155(3), 1151-1164 (1995).

73 Takahashi T, Tagami T, Yamazaki S et al. Immunologic self-tolerance maintained by $\mathrm{CD} 25\left(^{+}\right) \mathrm{CD} 4\left(^{+}\right)$regulatory $\mathrm{T}$ cells constitutively expressing cytotoxic T lymphocyte-associated antigen 4. J. Exp. Med. 192(2), 303-310 (2000).

74 Robert C, Thomas L, Bondarenko I et al. Ipilimumab plus dacarbazine for previously untreated metastatic melanoma. N. Engl. J. Med. 364(26), 2517-2526 (2011).

75 Hodi FS, O’Day SJ, Mcdermott DF et al. Improved survival with ipilimumab in patients with metastatic melanoma. N. Engl. J. Med. 363(8), 711-723 (2010).

76 Margolin K, Ernstoff MS, Hamid O et al. Ipilimumab in patients with melanoma and brain metastases: an open-label, Phase 2 trial. Lancet Oncol. 13(5), 459-465 (2012).

77 Fong B, Jin R, Wang X et al. Monitoring of regulatory $T$ cell frequencies and expression of CTLA- 4 on T cells, before and after DC vaccination, can predict survival in GBM patients. PloS ONE 7(4), e32614 (2012).

78 Sampson JH, Schmittling RJ, Archer GE et al. A pilot study of IL-2Ralpha blockade during lymphopenia depletes regulatory T-cells and correlates with enhanced immunity in patients with glioblastoma. PloS ONE 7(2), e31046 (2012). 
79 Dong H, Chen L. B7-H1 pathway and its role in the evasion of tumor immunity. J. Mol. Med. 81(5), 281-287 (2003).

80 Dong H, Strome SE, Salomao DR et al. Tumor-associated B7-H1 promotes T-cell apoptosis: a potential mechanism of immune evasion. Nat. Med. 8(8), 793-800 (2002).

81 Dong H, Zhu G, Tamada K, Chen L. B7-H1, a third member of the B7 family, co-stimulates T-cell proliferation and interleukin-10 secretion. Nat. Med. 5(12), 1365-1369 (1999).

82 Parsa AT, Waldron JS, Panner A et al. Loss of tumor suppressor PTEN function increases B7-H1 expression and immunoresistance in glioma. Nat. Med. 13(1), 84-88 (2007).
83 Han SJ, Ahn BJ, Waldron JS et al. Gamma interferon-mediated superinduction of B7-H1 in PTEN-deficient glioblastoma: a paradoxical mechanism of immune evasion. Neuroreport 20(18), 1597-1602 (2009).

84 Waldron JS, Yang I, Han S et al. Implications for immunotherapy of tumor-mediated T-cell apoptosis associated with loss of the tumor suppressor PTEN in glioblastoma. J. Clin. Neurosci. 17(12), 1543-1547 (2010).

85 Wheeler CJ, Das A, Liu G, Yu JS, Black KL. Clinical responsiveness of glioblastoma multiforme to chemotherapy after vaccination. Clin. Cancer Res. 10(16), 5316-5326 (2004).
86 Thomas AA, Ernstoff MS, Fadul CE. Immunotherapy for the treatment of glioblastoma. Cancer J. 18(1), 59-68 (2012).

\section{- Websites}

101 ClinicalTrials.gov. Phase III study of rindopepimut/GM-CSF in patients with newly diagnosed glioblastoma (ACT IV). http://clinicaltrials.gov/ct2/show/ NCT01480479

102 ClinicalTrials.gov. Study of a drug $\left[\mathrm{DCVax}^{\circledR}-\mathrm{L}\right]$ to treat newly diagnosed GBM brain cancer.

http://clinicaltrials.gov/ct2/show/NCT00045 968? term $=$ NCT00045968\& rank=1 